Paper

Title

\title{
Microstructures and Luminescent Properties of Ce-Doped Transparent Mica Glass-Ceramics
}

Authors'Names

\author{
Seiichi Taruta $^{\text {a,*, Yoshitomo Iwasaki }}{ }^{\text {a }}$, Hiromasa Nishikiori ${ }^{\text {a }}$, \\ Tomohiko Yamakami ${ }^{\text {a }}$, Tomohiro Yamaguchi ${ }^{\text {a }}$, \\ Kunio Kitajima ${ }^{a}$ and Kiyoshi Okada ${ }^{b}$
}

Authors' Affiliations

${ }^{\text {a }}$ Faculty of Engineering, Shinshu University, 4-17-1, Wakasato, Nagano 380-8553, Japan

b Materials and Structure Laboratory, Tokyo Institute of Technology, 4259, Nagatsuta, Midori-ku, Yokohama 226-8503, Japan

*Corresponding Author

Seiichi TARUTA

Department of Chemistry and Materials Engineering, Faculty of Engineering, Shinshu University

4-17-1 Wakasato, Nagano 380-8553, Japan

TEL: +81-26-269-5416

FAX: +81-26-269-5424

E-mail: staruta@shinshu-u.ac.jp 


\begin{abstract}
Transparent mica glass-ceramics were prepared by heating parent glasses that had been doped with $0.5-15 \mathrm{~mol}^{2} \mathrm{CeO}_{2}$. During the melting and heat treatment, $\mathrm{Ce}^{4+}$ ions in the specimens were reduced to $\mathrm{Ce}^{3+}$ ions, and one or both of these ion species were then replaced $\mathrm{Li}^{+}$ions in the interlayers of the separated mica crystals. However, scanning transmission electron microscope (STEM) and Z-contrast imaging revealed that the mica crystals did not contain the same amount of Ce. On excitation at $254 \mathrm{~nm}$, the parent glasses and glass-ceramics emitted blue light, which originated from the $5 \mathrm{~d}$ to $4 \mathrm{f}$ transition of the $\mathrm{Ce}^{3+}$ ions. The emission of the glass-ceramic containing a smaller amount of $\mathrm{Ce}$ was attributed to the $\mathrm{Ce}^{3+}$ ions in both the glass phase and the mica crystals, whereas that of the glass-ceramics containing a larger amount of $\mathrm{Ce}$ was caused mainly by $\mathrm{Ce}^{3+}$ ions in the mica crystals. The dependence of the emission band of the parent glasses on the amount of $\mathrm{Ce}$ was a unique feature of the Ce-doped transparent mica glass-ceramics and was not observed in previous studies of Eu-doped parent glasses and mica glass-ceramics.
\end{abstract}

Keywords: Cerium, Crystallization, Glass-ceramics, Mica, Luminescent properties 


\section{Introduction}

$\mathrm{Ce}^{3+}$ ions are well known as activators in phosphors. The emission spectra of $\mathrm{Ce}^{3+}$ ions consist of broad bands due to transition between $4 \mathrm{f}\left({ }^{2} \mathrm{~F}_{7 / 2}\right.$ and $\left.{ }^{2} \mathrm{~F}_{5 / 2}\right)$ and $5 \mathrm{~d}$ electronic states. Thus, depending on the host material, $\mathrm{Ce}^{3+}$-doped phosphors emit yellow, green, or blue light. Among these phosphors, $\mathrm{Ce}^{3+}$-doped yttrium aluminum garnet (YAG), which emits yellow light, has found wide use as a phosphor for white light-emitting diodes (LED). However, investigating the luminescent properties of $\mathrm{Ce}^{3+}$-doped compounds is of continued interest for the development of novel phosphors [1-14], particularly $\mathrm{Ce}^{3+}$-doped scintillators $[1,2,9,14]$, as the allowed $5 \mathrm{~d}-4 \mathrm{f}$ transition has a short lifetime and high quantum efficiency in the $10-40 \mathrm{~nm}$ range [1].

Transparent glass-ceramics are promising materials for white LED, laser materials, and optical amplifiers because light can easily penetrate into the interior of these host materials and activate phosphors located in the interior. Transparent oxyfluoride glass-ceramics, which consist of fluoride crystals dispersed throughout a continuous silicate glass, combine the optical advantages of rare-earth-doped fluoride crystals with the ease of forming and handling of conventional oxide glasses [15]. Recently, we succeeded in preparing novel machinable transparent glass-ceramics, in which the fluorine-micas were separated [16,17], and Eu-doped transparent mica glass-ceramics [18]. In the latter, the Eu-doped parent glasses emitted red light due to the $\mathrm{Eu}^{3+}$ ions that were added as $\mathrm{Eu}_{2} \mathrm{O}_{3}$, while the mica glass-ceramics emitted purple light due to not only $\mathrm{Eu}^{3+}$ ions, but also $\mathrm{Eu}^{2+}$ ions, which were reduced from $\mathrm{Eu}^{3+}$ ions on heating of the parent glasses in air. For this reason, transparent mica glass-ceramics are attractive host materials for phosphors.

Here, we investigated the preparation and luminescent properties of Ce-doped 
transparent mica glass-ceramics. Parent glasses doped with $0.5-15 \mathrm{~mol}_{0} \mathrm{CeO}_{2}$ were heated in air to prepare transparent mica glass-ceramics, and the influence of Ce-doping on the crystallization of the parent glasses and the microstructure of the obtained glass-ceramics was then investigated. In addition, the luminescent properties of the parent glasses and obtained glass-ceramics were estimated.

\section{Experimental procedure}

The composition of the base glass used in this study was 94.9 mass $\%$ $\mathrm{Li}_{1.5} \mathrm{Mg}_{3} \mathrm{AlSi}_{4.5} \mathrm{O}_{13.25} \mathrm{~F}_{2}$ and 5.1 mass $\% \mathrm{MgF}_{2}$. The base glass was doped with $0,0.5,5$, 10 , and $15 \mathrm{~mol}^{\circ} \mathrm{CeO}_{2}$ by melting the raw materials in a sealed platinum container and was then used to prepare several specimens of transparent mica glass-ceramics by heating the materials at $600-800{ }^{\circ} \mathrm{C}$ for $1 \mathrm{~h}$ in air, as previously described [16-18]. The prepared specimens are referred to as $\mathrm{Ce} 0, \mathrm{Ce} 05, \mathrm{Ce} 5, \mathrm{Ce} 10$ and $\mathrm{Ce} 15$ according to the respective amounts of added $\mathrm{CeO}_{2}$.

Thermal changes of the parent glasses were analyzed using an X-ray diffraction (XRD) analyzer. The microstructures of the glass-ceramics were observed using a field emission-type scanning electron microscope (FE-SEM), transmission electron microscope (TEM) with an energy dispersive X-ray (EDX) analyzer, and scanning TEM (STEM). The luminescent properties of the parent glasses and glass-ceramics with a thickness of $0.5 \mathrm{~mm}$ were analyzed at room temperature using a fluorescence spectrophotometer with the wavelength resolution of $1.0 \mathrm{~nm}$.

\section{Results and discussion}

\subsection{Influence of Ce-doping on crystallization and microstructure}


XRD patterns and photographs of the $\mathrm{Ce} 05$ parent glass and the heated $\mathrm{Ce} 05$ specimens are shown in Fig. 1. At a preparation temperature of $650{ }^{\circ} \mathrm{C}$, chondrodite $\left(\mathrm{Mg}_{5}\left(\mathrm{SiO}_{4}\right)_{2} \mathrm{~F}_{2}\right)$, which acts as nuclei for mica, and traces of mica were first observed in the XRD pattern. At $700{ }^{\circ} \mathrm{C}$, a large amount of mica was separated from the parent glass and the amount of chondrodite decreased. The obtained mica glass-ceramic was colorless and transparent. With increasing heating temperature, $\beta$-eucryptite $\left(\mathrm{LiAlSiO}_{4}\right)$ was detected in the XRD spectra, and the specimen began to appear white opaque. The largest amount of separated $\beta$-eucryptite and greatest opacity of the specimen occurred $800{ }^{\circ} \mathrm{C}$ ( $\beta$-eucryptite separated in the specimens might be $\beta$-eucryptite solid solution [16]). The observed crystallization process was similar to that of the parent glass to which Ce was not added (data not shown).

XRD patterns and photographs of the $\mathrm{Ce} 0-\mathrm{Ce} 15$ specimens heated at $700{ }^{\circ} \mathrm{C}$ are shown in Fig. 2. Each specimen separated a large amount of mica at $700{ }^{\circ} \mathrm{C}$ and appeared transparent. Moreover, the Ce10 and Ce15 specimens contained separated $\beta$-eucryptite and $\mathrm{Ce}_{2} \mathrm{O}_{3}$, and were brown in color. The separation of $\mathrm{Ce}_{2} \mathrm{O}_{3}$ indicates that $\mathrm{Ce}^{4+}$ ions, which were added to the specimens as $\mathrm{CeO}_{2}$, were reduced to $\mathrm{Ce}^{3+}$ ions, and the brown coloration means that both $\mathrm{Ce}^{3+}$ and $\mathrm{Ce}^{4+}$ ions were present in the specimens [7]. The reduction of $\mathrm{Ce}^{4+}$ to $\mathrm{Ce}^{3+}$ ions was likely caused by the evolution of fluorine from the specimens during the melting and heating treatments, which was the same mechanism with the reduction of $\mathrm{Eu}^{3+}$ to $\mathrm{Eu}^{2+}$ ions in $\mathrm{Eu}_{2} \mathrm{O}_{3}$-doped mica glass-ceramics [18].

The basal spacing $(c \cdot \sin \beta)$ and lattice constant $(b)$ of mica crystals in the specimens were measured. Regardless of Ce content and heating temperature, they are almost the same with those of mica crystals in $\mathrm{Ce} 0$ specimens and Eu-doped specimens. The basal spacing $(c \cdot \sin b)$ and lattice constant $(b)$ of the mica crystals separated in $\mathrm{Ce} 0$ 
specimens and Eu-doped specimens were shown in our previous studies [17,18], which indicate that mica crystals separated in this study were intermediate type between tetrasilicic type mica and trisilisic type mica. In addition, the our previous study reported that the composition of mica crystals in the specimens containing no rare-earth was $\mathrm{Li}\left(\mathrm{Mg}_{2+\mathrm{y}} \mathrm{Li}_{1-\mathrm{y}}\right)\left(\mathrm{Al}_{\mathrm{y}} \mathrm{Si}_{4-\mathrm{y}}\right) \mathrm{O}_{10} \mathrm{~F}_{2}(0<\mathrm{y}<1)$ [17]. Probably, the composition of mica crystals in this study was almost the same, but parts of Li ions in the interlayer were substituted by Ce ions.

To estimate the microstructure and distribution of $\mathrm{Ce}$ in the transparent mica glass-ceramics, the Ce5 specimen heated at $700{ }^{\circ} \mathrm{C}$ were subjected to TEM and EDX analysis (Fig. 3). The separation of many rod-like mica crystals was observed in the TEM images (Fig. 3(a) and 3(b)). The sizes of the separated crystals in the long- and short-axis directions were $<200$ and $<50 \mathrm{~nm}$, respectively. At high magnification, the mica was found to form a layered structure, with the layers piled towards the short-axis direction (Fig. 3(b)). In this structure, the short-axis direction was perpendicular to the direction of the basal plane of the mica, while the long axis corresponded to the $\mathrm{a}$ or $\mathrm{b}$ axis of mica. Numerous dark and light areas were also observed in the TEM images. To determine the difference in the composition of these areas, EDX spectra were measured on the dark (M) and light sites (G) in Fig 3(a), (c) and (d). The dark site was clearly a mica crystal based on morphology; however, it was not clear whether the light site was a mica crystal. In the EDX spectrum of $\mathrm{M}, \mathrm{Ce}$ peaks appeared together with $\mathrm{Mg}, \mathrm{Al}, \mathrm{Si}$, $\mathrm{O}$, and $\mathrm{F}$ peaks, demonstrating that $\mathrm{Ce}$ was contained in the micas. However, no $\mathrm{Ce}$ peaks were detected in the EDX spectrum of $\mathrm{G}$, although $\mathrm{Mg}, \mathrm{Al}, \mathrm{Si}, \mathrm{O}$, and $\mathrm{F}$ peaks were observed. Together, these spectra suggest that Ce was not distributed uniformly in the specimens.

STEM and Z-contrast images of the Ce10 specimen heated at $700{ }^{\circ} \mathrm{C}$ are shown in 
Fig. 4. As the Z-contrast is proportional to the square of the atomic number, this technique was used to evaluate the difference in Ce concentration in the specimen, with lighter areas in the image containing a large amount of Ce. In the STEM image the Ce10 specimen, which was taken in the identical location as the Z-contrast image, many rod-like mica crystals were observed (Fig. 4(a)). Several of the separated mica crystals (enclosed by solid circles in Fig. 4(a) and (b)) in the STEM image appeared as well-lighted areas in the corresponding Z-contrast image, whereas others (enclosed by dotted circles) were not detected in the Z-contrast image. These results confirmed that the mica crystals did not contain the same amount of Ce. In the separated mica crystals, $\mathrm{Ce}\left(\mathrm{Ce}^{3+}\right.$ and $\mathrm{Ce}^{4+}$ ions $)$ is likely located in the mica interlayers where it stabilizes the crystal structure of mica, as $\mathrm{Li}^{+}$ions are too small to exist in the interlayer and the size of $\mathrm{Ce}^{3+}$ and $\mathrm{Ce}^{4+}$ ions is larger than that of other anions present in the specimens. Thus, a single $\mathrm{Ce}^{3+}$ or $\mathrm{Ce}^{4+}$ ion was likely substituted for three or four $\mathrm{Li}^{+}$ions, respectively, in the interlayer. In addition, finer particles with sizes of $<50 \mathrm{~nm}$ were also detected in the specimens, as shown by arrows in Fig. 4 (a), and they appeared as lighted areas in the Z-contrast image. These particles might correspond to the $\mathrm{Ce}_{2} \mathrm{O}_{3}$ observed in the XRD spectrum of the Ce10 and Ce15 specimens.

The crystallite sizes in the b- and c-axis directions of mica separated in the $\mathrm{Ce} 0-\mathrm{Ce} 15$ specimens heated at $700{ }^{\circ} \mathrm{C}$ were determined from the $(060)$ and $(003)$ diffraction peaks, respectively, in the XRD patterns of each specimen according to the Scherrer equation (Fig. 5). The calculated crystallite sizes were smaller than those of the mica crystals observed in the STEM and Z-contrast images, which indicates the mica crystals observed in Figs. 3 and 4 consisted of 2-3 mica crystallites. As mentioned above, substitution of $\mathrm{Ce}^{3+}$ or $\mathrm{Ce}^{4+}$ ions for $\mathrm{Li}^{+}$ions in the interlayer leads to stabilization of the mica structure. In the case of the addition of $\leq 5 \mathrm{~mol} \% \mathrm{CeO}_{2}$ to the 
parent glass, the Ce content in the interlayer of mica was likely too low to sufficiently stabilize the mica structure. Consequently, the crystallite sizes of the micas separated in the $\mathrm{Ce} 05$ and $\mathrm{Ce} 5$ specimens were similar to those of micas in the $\mathrm{Ce} 0$ specimen. In contrast, the addition of $\geq 10 \mathrm{~mol} \% \mathrm{CeO}_{2}$ resulted in many $\mathrm{Ce}^{3+}$ and/or $\mathrm{Ce}^{4+}$ ions entering the mica interlayer, resulting in a more stable structure. Consequently, micas in the Ce10 and Ce15 specimens grew more than the other specimens. Thus, our results demonstrated that the crystallite sizes of the micas increased with increasing amount of doped $\mathrm{CeO}_{2}$ and with increasing heating temperature.

\subsection{Luminescent properties}

Emission and excitation spectra of the $\mathrm{Ce} 05$ and $\mathrm{Ce} 10$ specimens heated at $700{ }^{\circ} \mathrm{C}$ are shown in Fig. 6. The emission spectra peaks of the two specimens were observed at around 310 and $420 \mathrm{~nm}$, respectively, which originated from the $5 \mathrm{~d}-4 \mathrm{f}$ transition of the $\mathrm{Ce}^{3+}$ ions. The Ce05 specimen gave an excitation spectrum in the range of $240-360 \mathrm{~nm}$, whereas the Ce10 specimen displayed an excitation spectrum in a wider range (240-400 $\mathrm{nm}$ ), with a few peaks between $240-360 \mathrm{~nm}$ and also a clear peak at $360 \mathrm{~nm}$. The observed excitation spectra at wavelengths between $240-360 \mathrm{~nm}$ might be due to the

$\mathrm{Ce}^{3+}$ ions in the micas and/or glass phase, and the excitation peak at $360 \mathrm{~nm}$ in the Ce10 specimen might be caused by the $\mathrm{Ce}^{3+}$ ions in $\mathrm{Ce}_{2} \mathrm{O}_{3}$. However, the range and peak wavelength of the emission spectra was nearly independent of the wavelength of the excitation spectra. Thus the Ce10 specimen was the transparent phosphor which emitted blue light on excitation at near ultraviolet rays, especially wavelength of $315 \mathrm{~nm}$.

Emission spectra of the Ce05-Ce15 parent glasses and resulting specimens heated at $700{ }^{\circ} \mathrm{C}$, which were excited at $254 \mathrm{~nm}$, are shown in Fig. 7 . The emission intensity was the strongest for the $\mathrm{Ce} 05$ parent glass and decreased markedly due to the 
concentration quenching resulting from the addition of $\geq 5 \mathrm{~mol} \% \mathrm{CeO}_{2}$ (Fig. 7(a)). No intensity peaks were observed in the spectrum obtained for the Ce15 parent glass. In addition, the emission peak was shifted towards longer wavelengths with an increase in Ce content.

The emission peak of the heated $\mathrm{Ce} 05$ specimen appeared at nearly the same wavelength (approximately $370 \mathrm{~nm}$ ) with that of the $\mathrm{Ce} 05$ parent glass, but the emission intensity was lowered and the emission band became broader towards the longer wavelength side of the spectrum compared with those of the Ce05 parent glass. These results indicate that the emission spectrum of the heated $\mathrm{Ce} 05$ specimen was caused by the $\mathrm{Ce}^{3+}$ ions in both the glass phase and the micas. In the heated specimen, the amount of glass phase was decreased by the separation of mica, resulting in a lowering of the peak intensity at $370 \mathrm{~nm}$. In addition, because the emission spectrum of the $\mathrm{Ce}^{3+}$ ions in the mica appeared at the same wavelength range with those of the heated Ce 5 and Ce10 specimens (described below), the emission band of the heated Ce05 specimen was broader to the longer wavelength side of the spectrum. In contrast, the emission intensities of the heated Ce5 and Ce10 specimens were much larger than those of their respective parent glasses, their emission peaks appeared at almost the same wavelength and were shifted towards shorter wavelengths. Although the emission peak of the heated Ce15 specimen was almost undetectable, a very small peak was observed in the same wavelength range as the Ce5 and Ce10 specimen emission peaks. These results indicate that the emission spectra of the heated Ce5-Ce15 specimens were caused mainly by $\mathrm{Ce}^{3+}$ ions in the micas. Upon entry of $\mathrm{Ce}^{3+}$ ions into the mica interlayers, the influence of concentration quenching on emission would become weaker, resulting in the stronger emission intensities of such specimens than those of the corresponding parent glasses. Notably, however, the addition of $\geq 10 \mathrm{~mol} \% \mathrm{CeO}_{2}$ weakened the emission intensities of 
the heated specimens. If the doped Ce is uniformly distributed in the separated mica, the emission intensities of the specimens will be stronger.

The parent glasses and heated specimens in this study emitted blue light on excitation at $254 \mathrm{~nm}$. The dependence of the emission band of the parent glasses on the additive amount of $\mathrm{Ce}$ and the above-mentioned differences of the emission peak wavelengths between the parent glasses and the obtained mica glass-ceramics were unique features of the Ce-doped transparent mica glass-ceramics examined here. Such features were not reported for Eu-doped parent glasses and mica glass-ceramics [18].

\section{Conclusions}

Here, transparent mica glass-ceramics, in which many rod-like mica crystals were separated, could be prepared by heating the parent glasses that had been doped with 0.5-15mol\% $\mathrm{CeO}_{2}$. During the melting and heat treatment, $\mathrm{Ce}^{4+}$ ions, which were added as $\mathrm{CeO}_{2}$, were reduced to $\mathrm{Ce}^{3+}$ ions, and the $\mathrm{Ce}^{3+}$ and/or $\mathrm{Ce}^{4+}$ ions then replaced $\mathrm{Li}^{+}$ ions in the mica crystal interlayers. However, as revealed by STEM and Z-contrast imaging, the separated mica crystals did not contain the same amount of Ce. It was found that the crystallite sizes of the separated micas increased with increasing amount of added $\mathrm{CeO}_{2}$, and the result that was due to the increased stability of the micas with higher Ce content in the interlayers.

On excitation at $254 \mathrm{~nm}$, the parent glasses and the heated specimens emitted blue light, which originated from the $5 \mathrm{~d}$ to $4 \mathrm{f}$ transition of $\mathrm{Ce}^{3+}$ ions. With increasing Ce content of the parent glass, the emission intensity decreases due to the effect of concentration quenching, while the emission peak shifted the longer wavelength side of the spectrum. The emission spectrum of the heated specimen prepared from parent glass 
doped with $0.5 \mathrm{~mol} \% \mathrm{CeO}_{2}$ was caused by $\mathrm{Ce}^{3+}$ ions in both the glass phase and the micas. Consequently, this specimen showed the same emission peak wavelength as that of the corresponding parent glass, but it displayed weaker emission intensity and a broader emission band. In contrast, the emission spectra of the heated specimens prepared from parent glasses doped with $5-15 \mathrm{~mol}^{\circ} \mathrm{CeO}_{2}$ were caused mainly by $\mathrm{Ce}^{3+}$ ions in the micas. Thus, because numerous $\mathrm{Ce}^{3+}$ ions entered the mica interlayer, the influence of concentration quenching on emission became weaker and the emission intensities of such specimens became stronger than those of corresponding parent glasses.

The Ce-doped transparent mica glass-ceramics generated in this study exhibited unique luminescent properties that were clearly distinct from those of Eu-doped transparent mica glass-ceramics. This finding suggests that rare-earth-doped transparent mica glass-ceramics have unique luminescent properties depending on the type of rare-earth element used. 


\section{Acknowledgement}

This research was supported by the Collaboration Research Project of Materials and Structures Laboratory, Tokyo Institute of Technology. 


\section{References}

[1] B.K. Woo, A.G Joly, W. Chen, J. Lumin. 131 (2011) 49-53.

[2] D.K. Ingole, C.P. Joshi, S.V. Moharil, P.L. Muthal, S.M. Dhopte, J. Lumin. 130 (2010) 1194-1197.

[3] A. Katelnikovas, H. Bettentrup, D. Uhlich, S. Sakirzanovas, T. Jüstel, A. Kareiva, J. Lumin. 129 (2009) 1356-1361.

[4] Y.P. Naik, M. Mohapatra, N.D. Dahale, T.K. Seshagiri, V. Natarajan, S.V. Godbole, J. Lumin. 129 (2009) 1225-1229.

[5] L.Y. Cai, X.D. Wei, H. Li, Q.L. Liu, J. Lumin. 129 (2009) 165-168.

[6] J. Gomes, O.A. Serra, J. Mater. Sci. 43 (2008) 546-550.

[7] H. Takahashi, S. Yonezawa, M. Kawai, M. Takashima, J. Fluorine Chem. 129 (2008) 1114-1118.

[8] H.M.H. Fadlalla, C.C. Tang, S.Y. Wei, X.X. Ding, J. Lumin. 128 (2008) 1655-1659.

[9] J. Zhao, C. Guo, L. Zhang, J. Hu, J. Lumin. 122-123 (2007) 924-926.

[10] M. Raukas, A. Konrad, K.C. Misha, J. Lumin. 122-123 (2007) 773-775.

[11] N. Suriyamurthy, B.S. Panigrahi, J. Lumin. 127 (2007) 483-488.

[12] R. Asakura, T. Isobe, K. Kurokawa, T. Takagi, H. Aizawa, M. Ohkubo, J. Lumin. 127 (2007) 416-422.

[13] G.Q. Xu, Z.X. Zheng, W.M. Tang, Y.C. Wu, J. Lumin. 127 (2007) 151-156.

[14] X.-J. Liu, H.-L. Li, R.-J. Xie,Y. Zeng, L.-P. Huang, J. Lumin. 127 (2007) 75-80.

[15] G.L. Beall, L.R. Pinckney, J. Am. Ceram. Soc. 82 (1999) 5-16.

[16] S. Taruta, T. Ichinose, T. Yamaguchi, K. Kitajima, J. Non-Cryst. Solids 352 (2006) $5556-5563$. 
[17] S. Taruta, M. Suzuki, T. Yamaguchi, K. Kitajima, J. Non-Cryst. Solids 354 (2008) 848-855.

[18] S. Taruta, M. Matsuki, H. Nishikiori, T. Yamakami, T. Yamaguchi, K. Kitajima, Ceram. Int. 36 (2010) 1303-1309. 


\section{Figure captions}

Fig. 1. (a) XRD patterns and (b) images of $\mathrm{Ce} 05$ parent glass and the $\mathrm{Ce} 05$ specimen heated at $600-800{ }^{\circ} \mathrm{C}$ for $1 \mathrm{~h}$.

Fig. 2. (a) XRD patterns and (b) images of $\mathrm{Ce} 0, \mathrm{Ce} 05, \mathrm{Ce} 5, \mathrm{Ce} 10$, and $\mathrm{Ce} 15$ specimens heated at $700{ }^{\circ} \mathrm{C}$ for $1 \mathrm{~h}$.

Fig. 3. TEM images of $\mathrm{Ce} 5$ specimen heated at $700{ }^{\circ} \mathrm{C}$ for $1 \mathrm{~h}$; (a) low magnification and (b) high magnification. EDX spectra of (c) dark site (M) and (d) light site (G) in (a)

Fig. 4. (a) STEM and (b) Z-contrast images of Ce10 specimen heated at $700{ }^{\circ} \mathrm{C}$ for $1 \mathrm{~h}$. Solid and dotted ovals show micas with higher and lower Ce content, respectively, while arrows indicate $\mathrm{Ce}_{2} \mathrm{O}_{3}$ particles.

Fig. 5. Crystallite sizes of b-axis direction $(\bullet)$ and c-axis direction $(\bullet)$ of mica separated in $\mathrm{Ce} 0, \mathrm{Ce} 05, \mathrm{Ce} 5, \mathrm{Ce} 10$, and $\mathrm{Ce} 15$ specimens heated at $700{ }^{\circ} \mathrm{C}$ for $1 \mathrm{~h}$.

Fig. 6. Emission (solid line) and excitation spectra (dotted line) of (a) Ce05 and (b) Ce10 specimens heated at $700{ }^{\circ} \mathrm{C}$ for $1 \mathrm{~h}$.

Fig. 7. Emission spectra of (a) Ce05-Ce15 parent glasses and (b) $\mathrm{Ce} 05-\mathrm{Ce} 15$ specimens heated at $700{ }^{\circ} \mathrm{C}$ for $1 \mathrm{~h}$; excitation wavelength, $\lambda_{\mathrm{ex}}=245 \mathrm{~nm}$. 


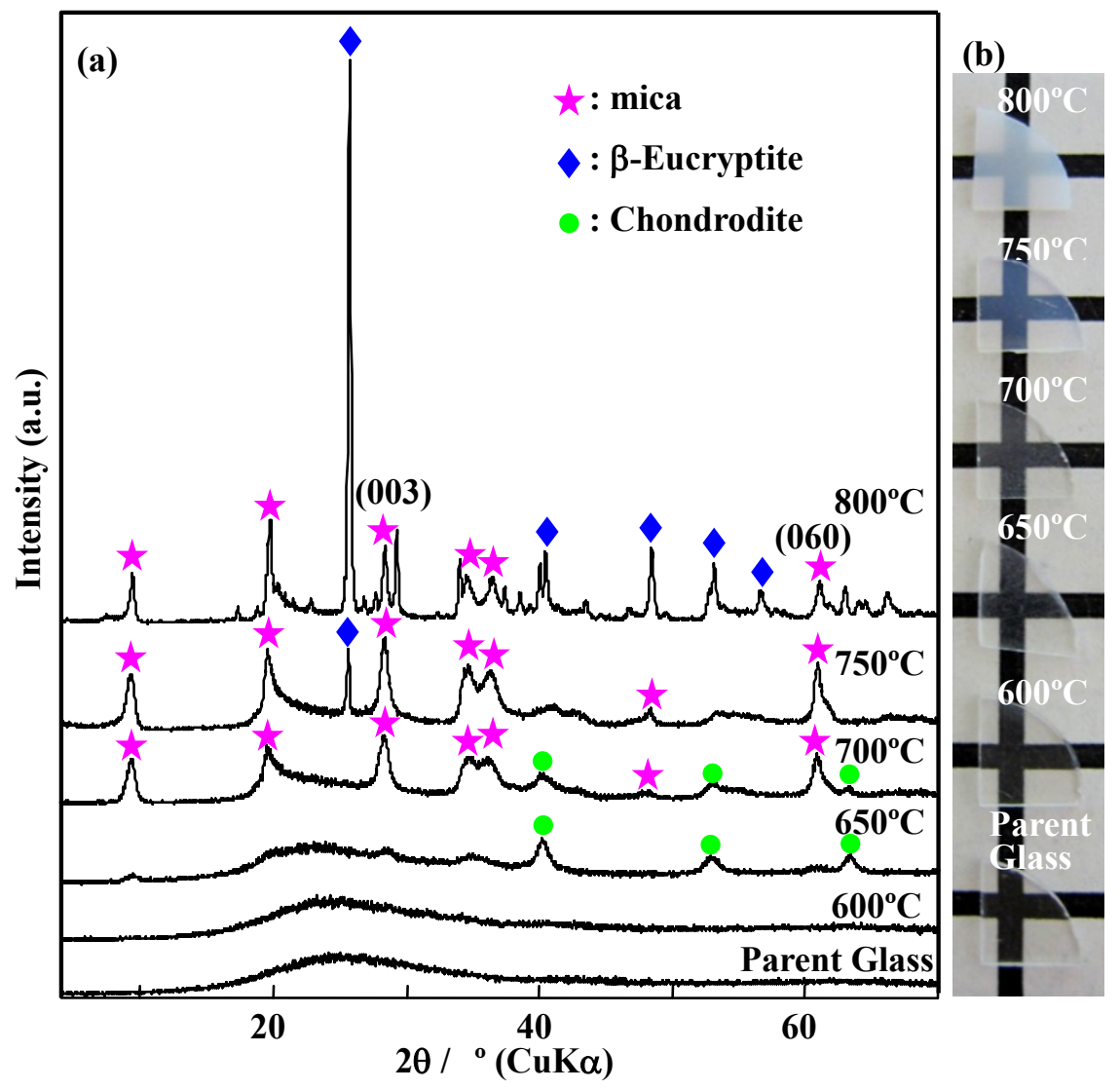

Fig. 1. (a) XRD patterns and (b) images of Ce05 parent glass and the Ce05 specimen heated at $600-800{ }^{\circ} \mathrm{C}$ for $1 \mathrm{~h}$. 


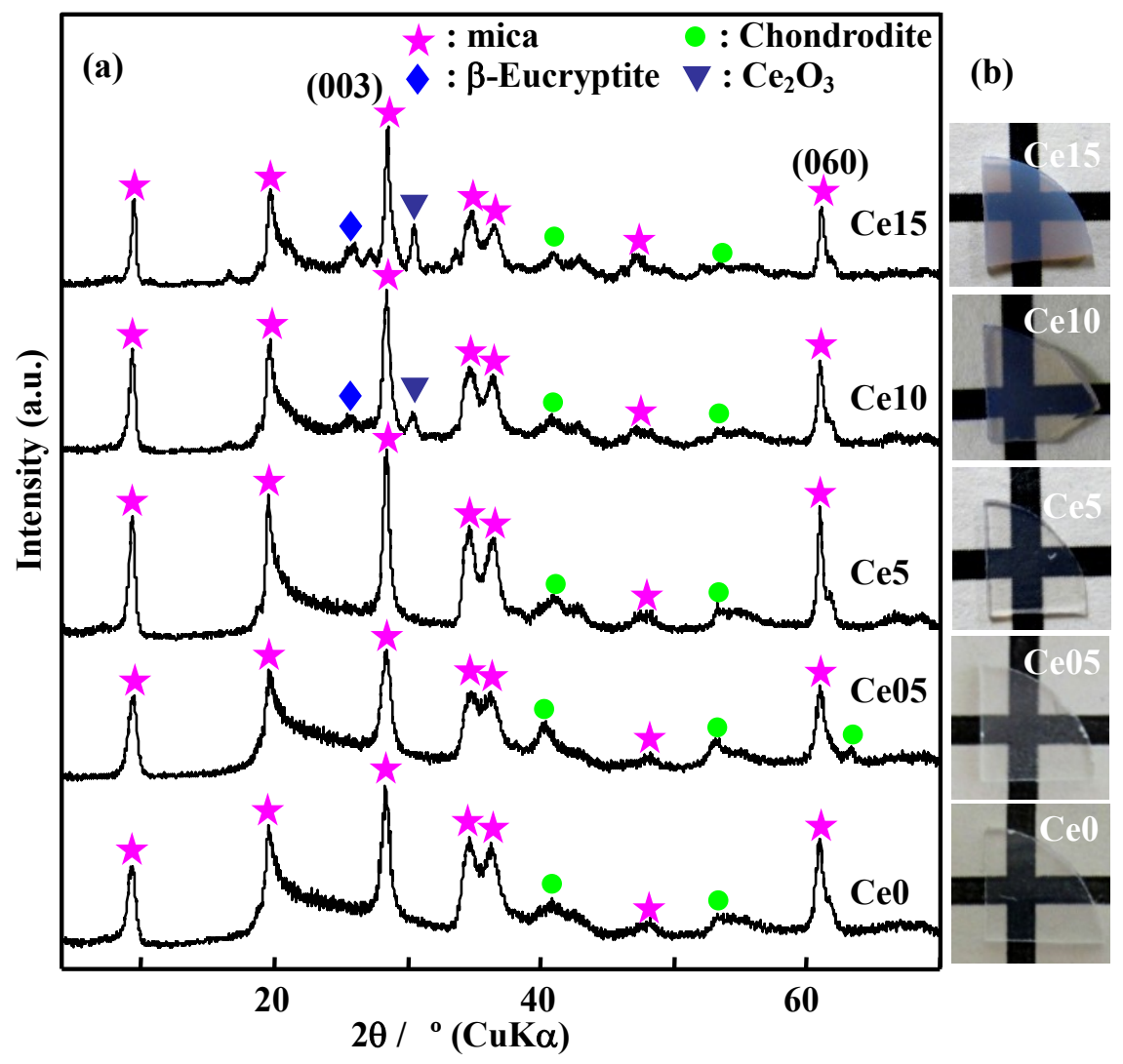

Fig. 2. (a) XRD patterns and (b) images of $\mathrm{Ce} 0, \mathrm{Ce} 05, \mathrm{Ce} 5, \mathrm{Ce} 10$, and Ce15 specimens heated at $700{ }^{\circ} \mathrm{C}$ for $1 \mathrm{~h}$. 

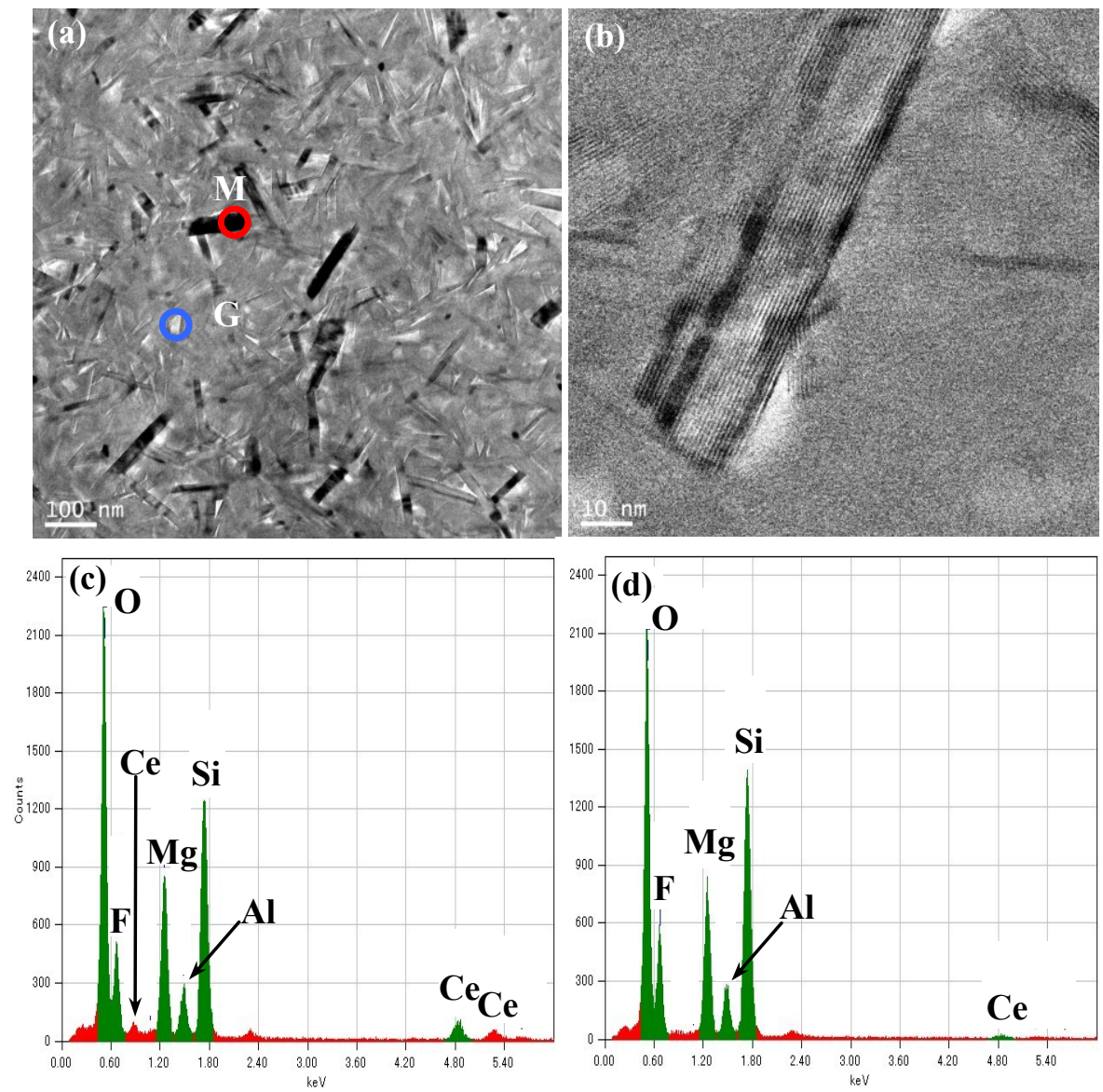

Fig. 3. TEM images of Ce5 specimen heated at $700{ }^{\circ} \mathrm{C}$ for $1 \mathrm{~h}$; (a) low magnification and (b) high magnification. EDX spectra of (c) dark site (M) and (d) light site (G) in (a). 

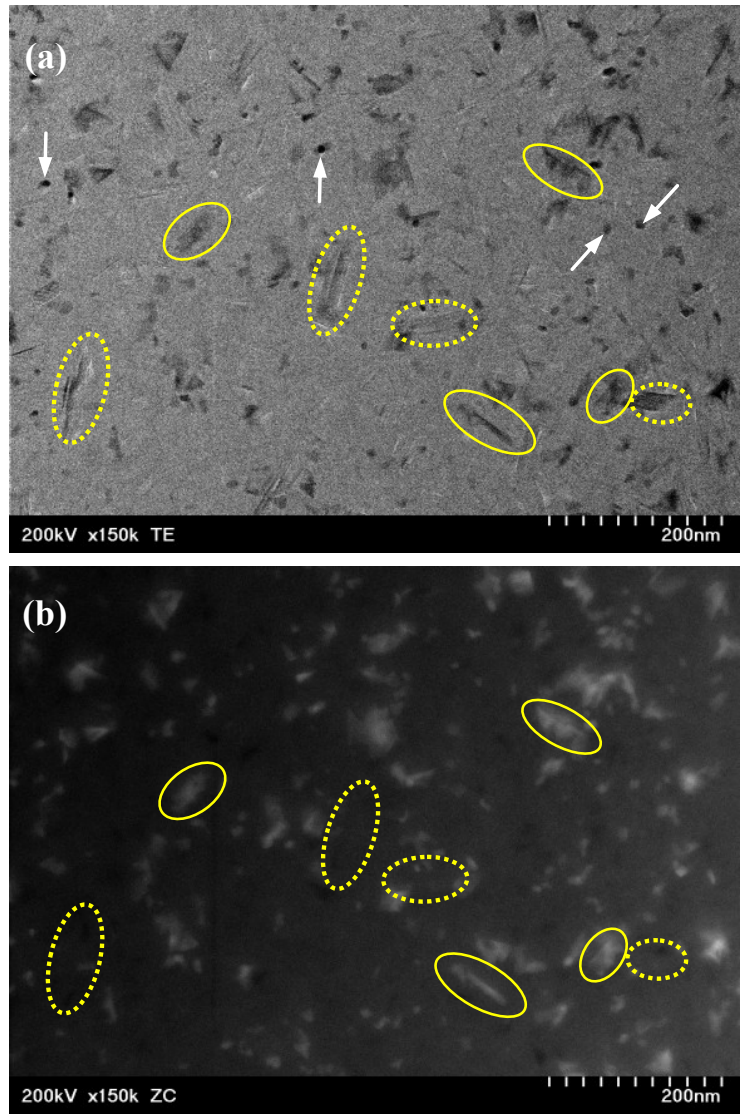

Fig. 4. (a) STEM and (b) Z-contrast images of Ce10 specimen heated at $700{ }^{\circ} \mathrm{C}$ for $1 \mathrm{~h}$. Solid and dotted ovals show micas with higher and lower Ce content, respectively, while arrows indicate $\mathrm{Ce}_{2} \mathrm{O}_{3}$ particles. 


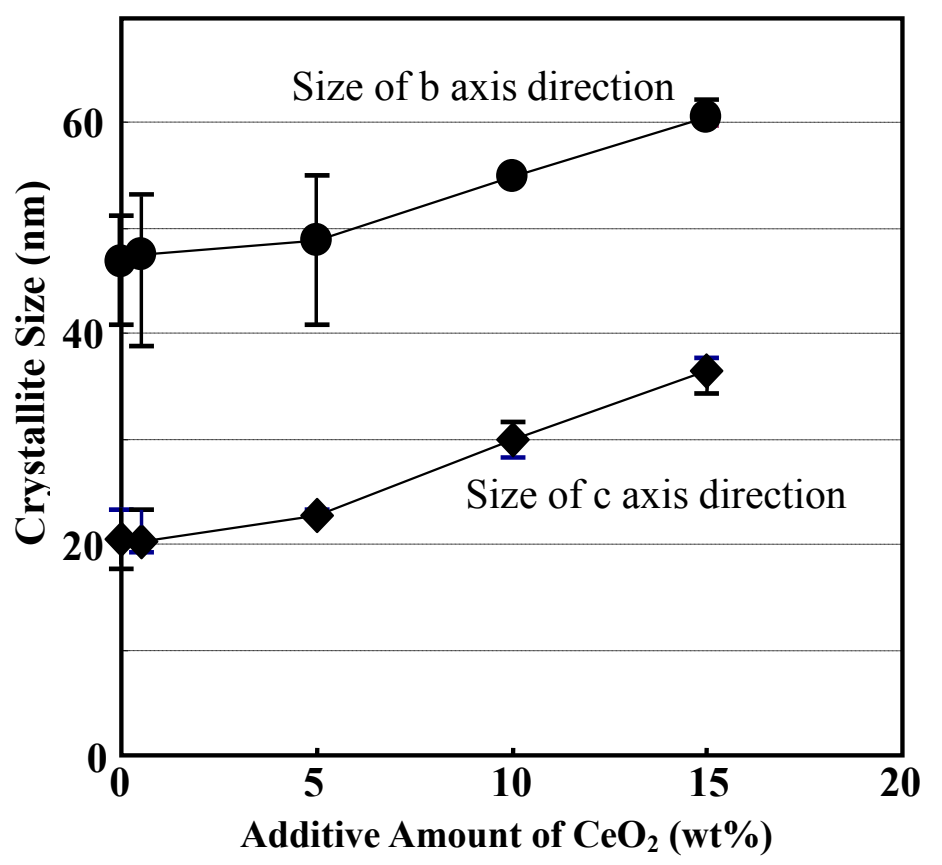

Fig. 5. Crystallite sizes of b-axis direction $(\bullet)$ and c-axis direction $(\diamond)$ of mica separated in $\mathrm{Ce} 0, \mathrm{Ce} 05, \mathrm{Ce} 5, \mathrm{Ce} 10$, and $\mathrm{Ce} 15$ specimens heated at $700{ }^{\circ} \mathrm{C}$ for $1 \mathrm{~h}$ 

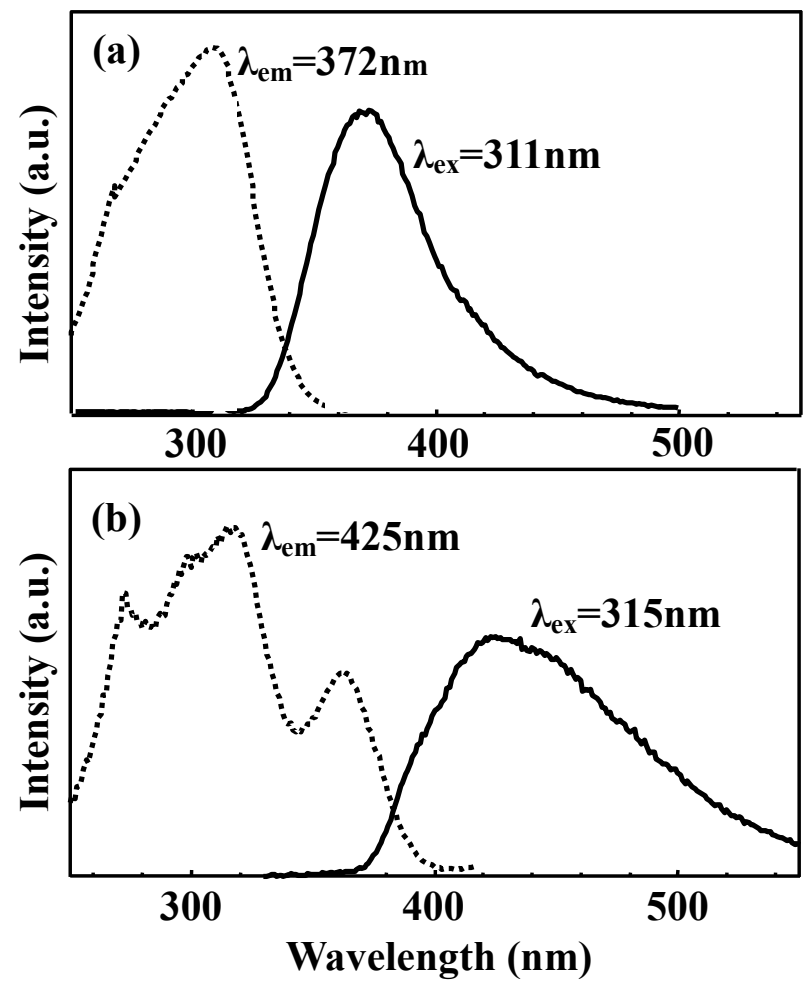

Fig. 6. Emission (solid line) and excitation spectra (dotted line) of (a) $\mathrm{Ce} 05$ and (b) $\mathrm{Ce} 10$ specimens heated at $700{ }^{\circ} \mathrm{C}$ for $1 \mathrm{~h}$. 


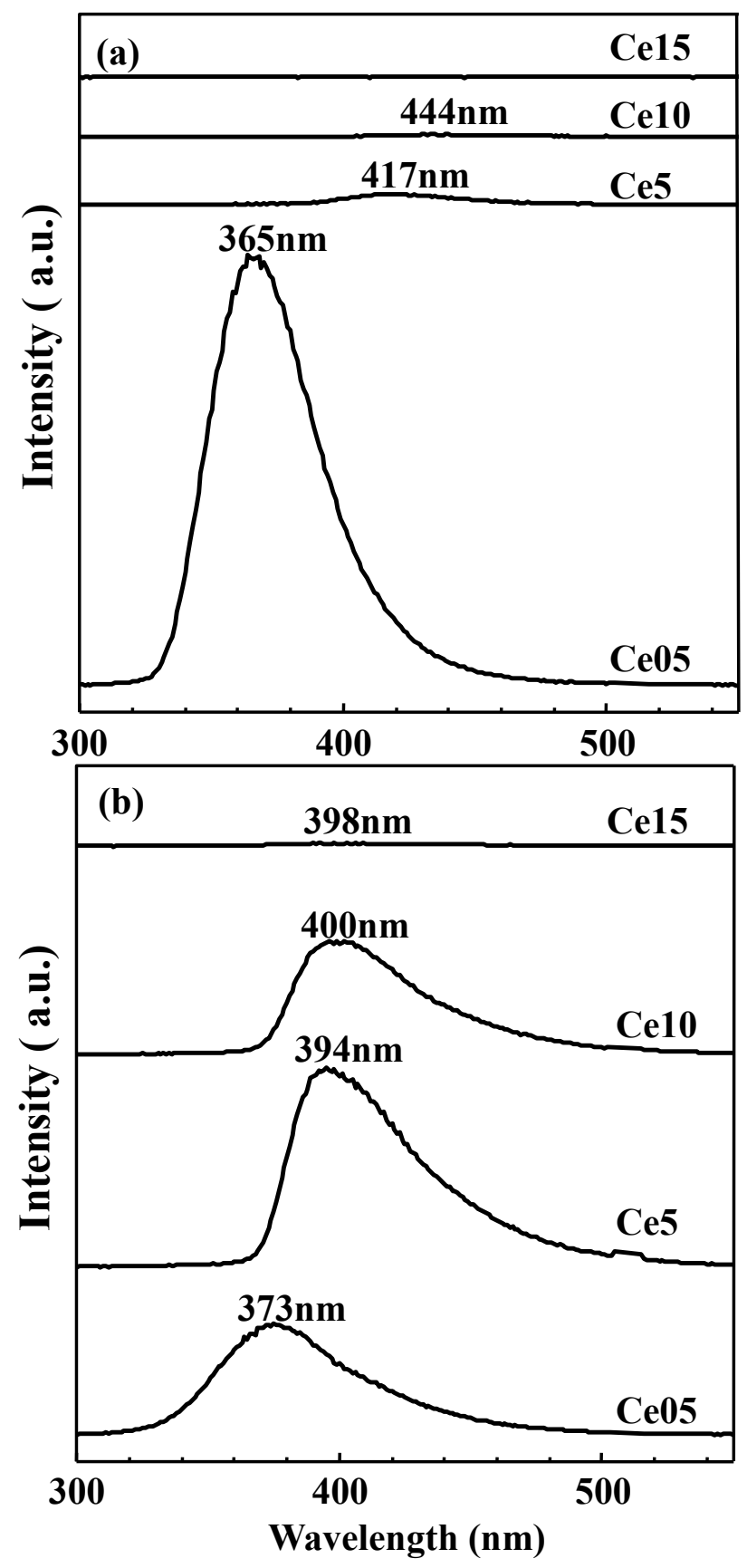

Fig. 7. Emission spectra of (a) Ce05-Ce15 parent glasses and (b) Ce05-Ce15 specimens heated at $700{ }^{\circ} \mathrm{C}$ for $1 \mathrm{~h}$; excitation wavelength, $\lambda_{\mathrm{ex}}=245 \mathrm{~nm}$. 